\title{
Copper mediated controlled radical copolymerization of styrene and 2-ethylhexyl acrylate and determination of their reactivity ratios
}

\author{
Bishnu P. Koiry and Nikhil K. Singha* \\ Rubber Technology Centre, Indian Institute of Technology Kharagpur, Kharagpur, India
}

Edited by:

Clemens Kilian Weiss, Universtiy of Applied Science Bingen, Germany

\section{Reviewed by:}

Frederik Roman Wurm, Max Planck Institute for Polymer Research, Germany

Yasuhiro Matsuda, Shizuoka

University, Japan

Jerome Claverie, Université du

Québec à Montréal, Canada

\section{*Correspondence:}

Nikhil K. Singha, Rubber Technology

Centre, Indian Institute of

Technology Kharagpur, Kharagpur

721302, West Bengal, India

e-mail:nks@rtc.iitkgp.ernet.in
Copolymerization is an important synthetic tool to prepare polymers with desirable combination of properties which are difficult to achieve from the different homopolymers concerned. This investigation reports the copolymerization of 2-ethylhexyl acrylate (EHA) and styrene using copper bromide $(\mathrm{CuBr})$ as catalyst in combination with $\mathrm{N}, \mathrm{N}, \mathrm{N}^{\prime}, \mathrm{N}^{\prime \prime}, \mathrm{N}^{\prime \prime}$ - pentamethyldiethylenetriamine (PMDETA) as ligand and 1-phenylethyl bromide ( $\mathrm{PEBr}$ ) as initiator. Linear kinetic plot and linear increase in molecular weights vs. conversion indicate that copolymerization reactions were controlled. The copolymer composition was calculated using ${ }^{1} \mathrm{H}$ NMR studies. The reactivity ratio of styrene and EHA ( $r_{1}$ and $\left.r_{2}\right)$ were determined using the Finemann-Ross (FR), inverted Finemann-Ross (IFR), and Kelen-Tudos (KT) methods. Thermal properties of the copolymers were also studied by using TGA and DSC analysis.

Keywords: controlled radical polymerization, ATRP, polystyrene, poly(2-ethylhexyl acrylate), copolymers, reactivity ratio, thermal properties

\section{INTRODUCTION}

The homopolymer and copolymers of 2-ethylhexyl acrylate (EHA) have very good film formation characteristics and have very good low temperature flexibility, because of the presence of branched and longer alkyl pendant group in the EHA. They have also low volume shrinkage. So the copolymers of EHA are widely used in paints, coating and adhesive applications (Skeist, 1977; Plessis et al., 2001; Webster and Crain, 2002). Copolymerization is an important synthetic tool which can control the thermal and mechanical properties of the polymers (Kavousian et al., 2004). In the copolymers of styrene and EHA, the properties of the copolymers can be monitored by controlled incorporation of the respective comonomers styrene and EHA. Polystyrene possess high glass transition temperature, $T_{\mathrm{g}}\left(\sim 100^{\circ} \mathrm{C}\right)$ where as poly(2-ethylhexyl acrylate) (PEHA) has low $T_{\mathrm{g}}$ of $-60^{\circ} \mathrm{C}$. Copolymers of styrene and EHA are important components for hard coating (Plessis et al., 2001) and also are used as blend compatibilizers (Haldankar, 2001). Conventional free radical polymerization (FRP) leads to uncontrolled molecular weight and broad dispersity $(\boldsymbol{\theta})$. There is also gel formation tendency, because of the several side reactions during FRP. This makes them difficult to apply for paints and coating material application owing to high viscosity (Solomon and Moad, 1995; Odian, 2004). Since 1990s there have been spectacular advances in the field of controlled radical polymerization (CRP). There were several CRP techniques namely, atom transfer radical polymerization (ATRP) (Kamigaito et al., 2001; Matyjaszewski and Jia, 2001; Kavitha and Singha, 2008), nitroxide-mediated polymerization (NMP) (Harth et al., 2001; Hawker et al., 2001), and reversible addition-fragmentation chain transfer (RAFT) (Chiefari et al.,
1998; Moad et al., 2000; Moad, 2006; Barner-Kowollik, 2008). Among the different CRP techniques, ATRP is applicable to polymerize wide range of monomers and can be carried out at wide range of temperature $\left(-20\right.$ to $\left.200^{\circ} \mathrm{C}\right)$ (Haloi et al., 2009). ATRP has been successfully applied to synthesize a wide range of polymers with varied molecular weights, different architectures, functionalities etc. Transition metal catalyzed CRP known as ATRP is an important CRP method (Matyjaszewski, 2000) which is carried out in presence of an active alkyl halide using a transition metal halide as catalyst in combination with a suitable ligand (Matyjaszewski and Jia, 2001). A wide variety of copolymers can be prepared via ATRP with controlled molecular weight, functionality, and low dispersity. There are several reports on the copolymerization of different acrylate monomers using ATRP and determination of their reactivity ratios. The reactivity ratios are important parameters for a set of monomer. The reactivity ratios of monomers predict the copolymer composition as well as the sequence distribution of the comonomers. It also predicts the properties of the copolymer. ATRP provides random copolymer with similar chain compositions which is very much different from FRP (Matyjaszewski, 2002). During the polymerization reaction, the polymer chains grow simultaneously and thus all the polymer chains have same composition. However, in FRP macromolecular chains start growing at different times during the polymerization and the monomer composition continuously changes. As a result, in FRP the different chains will have different compositions in the end (Solomon and Moad, 1995). The reactivity ratios of co-monomers in a CRP are somewhat different from the same in FRP. This is because in CRP processes there is intermittent activation-deactivation of the active species 
which results in different rates of consumption of comonomers (Matyjaszewski, 2002; Braunecker and Matyjaszewski, 2007). For example, Mignard et al. reported the reactivity ratios of the copolymerization of styrene and butyl acrylate (BA) via NMP at $120^{\circ} \mathrm{C}$ in solution. They reported the reactivity ratios for styrene and BA within the range of 0.60-1.2 $\left(\mathrm{r}_{\text {styrene }}\right)$ and $0.16-0.29\left(\mathrm{r}_{\mathrm{BA}}\right)$ respectively (Mignard et al., 2004). Arehart and Matyjaszewski reported the reactivity ratios of styrene and BA prepared via ATRP at $110^{\circ} \mathrm{C}$ in solution. They reported the reactivity ratios for styrene and $\mathrm{BA}$ as $0.68<\mathrm{r}_{\text {styrene }}<0.82$ and $0.22<\mathrm{r}_{\mathrm{BA}}<0.26$ respectively (Arehart and Matyjaszewski, 1999). Chambard et al. reported the copolymerization of styrene and BA prepared in bulk via FRP. The reactivity ratios of styrene and BA prepared via FRP at $90^{\circ} \mathrm{C}$ were reported to be 0.95 and 0.20 respectively (Chambard et al., 1999). Ziegler and Matyjaszewski reported the variation in reactivity ratios of MMA and BA with the change in ligand from 4,4'-di(5-nonyl)-2,2'-bipyridine (dNbpy) $\left(\mathrm{r}_{\mathrm{MMA}}=2.52\right.$, $\left.\mathrm{r}_{\mathrm{BA}}=0.26\right)$ to $\mathrm{N}, \mathrm{N}, \mathrm{N}^{\prime}, \mathrm{N}^{\prime \prime}, \mathrm{N}^{\prime \prime}$-pentamethyldiethylenetriamine (PMDETA) $\quad\left(\mathrm{r}_{\mathrm{MMA}}=3.15\right.$, and $\mathrm{r}_{\mathrm{BA}}=0.37$ ) (Ziegler and Matyjaszewski, 2001). Lessard et al. reported the reactivity ratios of styrene and tert-butyl acrylate $(t-\mathrm{BA})$ prepared via NMP at $115^{\circ} \mathrm{C}$ in bulk as $r_{t-\mathrm{BA}}=0.09-0.12$ and $\mathrm{r}_{\text {Styrene }}=0.40-0.49$ (Lessard et al., 2007). We reported the ATRP of furfuryl methylacrylate and methyl methacrylate (Kavitha and Singha, 2007), 2-ethylhexyl acrylate and glycidyl methacrylate (Haloi et al., 2009). However, there is no report on the ATRP of styrene and EHA and to determine their reactivity ratios. The objective of this investigation is to study the copolymerization of styrene and EHA via ATRP and to determine their reactivity ratios. The reactivity ratios of styrene and EHA were calculated using Finemann-Ross (FR), inverted Finemann-Ross (IFR), and Kelen-Tudos (KT) methods (Fineman and Ross, 1950; Kelen et al., 1980; Makrikosta et al., 2005).

\section{MATERIALS AND METHODS}

The monomers, 2-ethylhexyl acrylate (EHA) (Aldrich, USA) and styrene (Jyoti Chemicals, Mumbai) were purified by vacuum distillation. $\mathrm{CuBr}$ (Aldrich, USA) was purified by washing with glacial acetic acid, and then it was washed thoroughly with diethyl ether and was finally dried under vacuum. Phenyl ethylbromide (PEBr) (97\%) and $\mathrm{N}, \mathrm{N}, \mathrm{N}^{\prime}, \mathrm{N}^{\prime \prime}, \mathrm{N}^{\prime \prime}-$ pentamethyldiethylenetriamine (PMDETA) (97\%) were purchased from Aldrich, USA and were used as received.

\section{CHARACTERIZATION}

Number average molecular weight (Mn, GPC) and dispersity (Đ) were determined by Gel Permeation Chromatography (GPC). GPC analysis was carried out at room temperature using a Viscotek GPC equipped with a refractive index detector (Model VE3580), two ViscoGEL GPC columns (model GMHHR-M \# 17392) connected in series. GPC analysis was carried out using tetrahydrofuran as eluent at a flow rate of $1 \mathrm{ml} / \mathrm{min}$. Linear and narrow disperse polystyrene was used as calibration standard and Viscotek OMNI-01 software was used for data processing.

${ }^{1} \mathrm{H}$ NMR spectra of the polymers were recorded on a $200 \mathrm{MHz}$ Brucker NMR spectrometer using $\mathrm{CDCl}_{3}$ as solvent which had a small amount of tetramethylsilane (TMS) as an internal standard.
Differential scanning calorimetry (DSC) analysis was carried out by using TA Instrument (DSC Q100 V8.1 Build 251) under nitrogen atmosphere at a heating rate of $10^{\circ} \mathrm{C} / \mathrm{min}$ within a temperature range of $-100^{\circ} \mathrm{C}$ to $+150^{\circ} \mathrm{C}$. The baseline calibration was done by scanning the temperature domain with the help of an empty pan. The enthalpy was calibrated by using indium standard and the heat capacity was calibrated by using the sapphire disc that was supplied by TA instrument. The glass transition temperature $\left(T_{\mathrm{g}}\right)$ was determined from the plot of heat flow vs. temperature in the second heating scan in the DSC analysis.

Thermogravimetric analysis (TGA) was carried out by using a TA Instrument $(\mathrm{Q} 50)$ at a heating rate of $20^{\circ} \mathrm{C} / \mathrm{min}$ in the temperature range of $30-600^{\circ} \mathrm{C}$ in nitrogen atmosphere. TGA analyzer consists of high precision balance with a pan which was placed in a small electrically heated oven. The temperature was measured accurately with the help of a thermocouple. From the plot of weight percent vs. temperature the polymer degradation temperature was determined.

\section{SYNTHESIS OF COPOLYMERS OF STYRENE AND EHA VIA ATOM TRANSFER RADICAL COPOLYMERIZATION (ATRCP)}

The polymerization reaction was carried out in a Schlenk tube. In a typical ATRP reaction EHA $(4.82 \mathrm{~g}, 26.1 \mathrm{mmol})$, styrene $(0.909 \mathrm{~g}, 8.7 \mathrm{mmol})$ and $\mathrm{CuBr}(0.050 \mathrm{~g}, 0.35 \mathrm{mmol})$ were accurately weighed and transferred to the Schlenk tube. The PMDETA ligand $(0.0604 \mathrm{~g}, 0.35 \mathrm{mmol})$ was then added to the reaction tube. Oxygen was removed from the reaction mixture by passing nitrogen through the reaction tube. The polymerization was started by adding $\operatorname{PEBr}(0.0646 \mathrm{~g}, 0.35 \mathrm{mmol})$ and was carried out at $90^{\circ} \mathrm{C}$. Aliquot samples were taken out at different time intervals and were used to calculate the conversion by gravimetric method. The samples were also used to find out the molecular weight by GPC. The final product was diluted with THF and was purified by passing through alumina column to remove the copper catalyst. The same procedure was adopted for other feed ratios of ATRcP (atom transfer radical copolymerization) of EHA and styrene.

\section{HOMOPOLYMERIZATION OF STYRENE VIA ATOM TRANSFER RADICAL POLYMERIZATION (ATRP)}

The homopolymerization of styrene was carried out in bulk in a Schlenk tube equipped with silicone septum and magnetic stirring bar. In the Schlenk tube styrene $(4.5 \mathrm{~g}, 43.2 \mathrm{mmol}), \mathrm{CuBr}$ $(0.031 \mathrm{~g}, 0.21 \mathrm{mmol})$ and PMDETA $(0.037 \mathrm{~g}, 0.21 \mathrm{mmol})$ were weighed and degassed by passing nitrogen gas for $15 \mathrm{~min}$. The reaction was started by adding $\operatorname{PEBr}(0.040 \mathrm{~g}, 0.21 \mathrm{mmol})$ in the mixture. The reaction was carried out at $110^{\circ} \mathrm{C}$ for $6 \mathrm{~h} .{ }^{1} \mathrm{H}$ NMR $\left(\mathrm{CDCl}_{3}, 200 \mathrm{MHz}\right): \delta$ (in ppm) $=6.4-7.2$ (phenyl protons of polystyrene) and 1.4-2.2 ppm ( $-\mathrm{CH}_{2}-$ and $>\mathrm{CH}-$ protons).

\section{SYNTHESIS OF DIBLOCK COPOLYMER OF POLYSTYRENE WITH EHA VIA ATRP}

The homopolymer of polystyrene (i.e., PS-Br) was used as macroinitiator for the synthesis of diblock copolymer of styrene and EHA. The macroinitiator, PS- $\mathrm{Br}(1.0 \mathrm{~g}, 0.066 \mathrm{mmol})$ was taken in a Schlenk tube and was dissolved in THF solvent into which $\mathrm{CuBr}(0.009 \mathrm{~g}, 0.069 \mathrm{mmol})$ and PMDETA $(0.017 \mathrm{~g}$, $0.10 \mathrm{mmol})$ were added followed by EHA $(1 \mathrm{~g}, 5.4 \mathrm{mmol})$. The 
polymerization reaction was carried out at $90^{\circ} \mathrm{C}$ for $6 \mathrm{~h}$. The polymer obtained was dissolved in THF and was purified by passing through basic alumina column and then precipitated in methanol.

\section{RESULTS AND DISCUSSION}

Copolymerization of styrene and 2-ethylhexyl acrylate was carried out via ATRcP (shown in Scheme 1) at different feed ratios by using phenylethylbromide $(\mathrm{PEBr})$ as initiator, $\mathrm{CuBr}$ as catalyst in combination with PMDETA as a ligand. From the kinetic plot of $\ln (1 / 1-\mathrm{X})$ (where $\mathrm{X}$ is the percent conversion of monomer) vs. time, it was observed that the value of $\ln (1 / 1-\mathrm{X})$ was linearly increased with time (Figure 1). This linear dependency is the characteristics of the controlled polymerization reaction which follows the first order kinetics. Figure 1 showed that with increase in styrene content in the feed the rate of polymerization increased (Jianying et al., 2006). Figure 2 infers that there was linear increase in molecular weight with conversion and dispersity

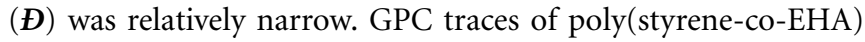
(50:50) (sample 3 of Table 1 ) is shown in supplementary section (Figure S1). It indicates the controlled nature of the copolymerization reaction. Table 1 summarizes the feed ratio as well as the copolymer composition of the different copolymerization reactions.

\section{STRUCTURAL CHARACTERIZATION AND COPOLYMER COMPOSITION}

The structural characterization and copolymer composition were determined by ${ }^{1} \mathrm{H}$ NMR spectroscopy. Figure 3 shows the ${ }^{1} \mathrm{H}$ NMR spectra of poly(styrene-co-EHA) of 40:60 feed ratio. The resonance at $\delta=0.8 \mathrm{ppm}$ is due to the $-\mathrm{CH}_{3}$ protons of PEHA part. The broad resonances at $\delta=1.0$ to $2.1 \mathrm{ppm}$ are due to the different $-\mathrm{CH}_{2}-$ and $>\mathrm{CH}-$ protons of pendant group of PEHA part as well as those of the main chain backbone of the copolymer. The resonances at $\delta=6.5-7.1 \mathrm{ppm}$ are due to the different aromatic protons of polystyrene part. The resonances at $3.8 \mathrm{ppm}$ are due to $-\mathrm{OCH}_{2}-$ protons of PEHA part. The distinct resonances at 6.5-7.3 for five aromatic protons of styrene and $3.8 \mathrm{ppm}$ for two protons of EHA were used to calculate the composition of the copolymer of styrene and EHA. The copolymer composition was determined by the equation (1) as shown below

$$
F_{E H A}=\frac{5 A}{5 A+2 B} \times 100
$$

where, $\mathrm{A}$ and $\mathrm{B}$ represent the integral area at $\delta=3.7$ and $\delta=$ 6.5-7.3 ppm for $-\mathrm{OCH}_{2}$ - protons in PEHA and aromatic protons of polystyrene unit respectively.

\section{REACTIVITY RATIO DETERMINATION}

In the copolymerization of styrene (1) and EHA (2) the reactivity ratio $r_{1}$ is defined as $k_{11} / k_{12}$, where $k_{11}$ is the rate constant of the reaction between the growing polymer chain carrying free radical of styrene as the terminal unit and styrene (homo propagation) and $k_{12}$ is the rate constant of the reaction between the same reactive chain end and the EHA monomer. Similarly the reactivity ratio $r_{2}$ is also defined as $k_{22} / k_{21}$, where $k_{22}$ is the rate constant of homo propagation reaction between the growing

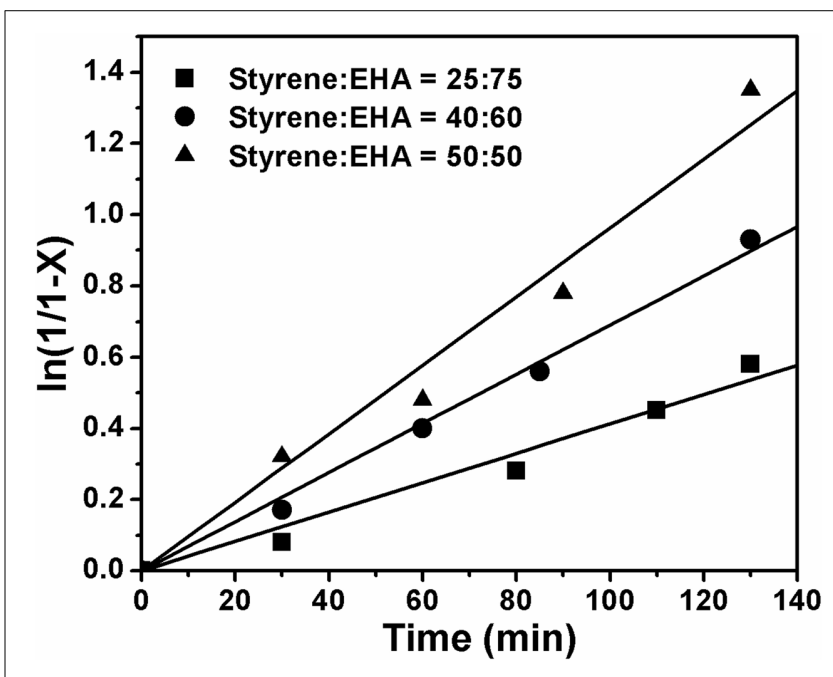

FIGURE 1 | Kinetic plot of $\ln [1 /(1-X)]$ vs time for copolymerization of styrene and EHA. $[\mathrm{PEBr}]:[\mathrm{M}]_{0}:[\mathrm{CuBr}]:[\mathrm{PMDETA}]=1: 100: 1: 1$, at $90^{\circ} \mathrm{C}$.

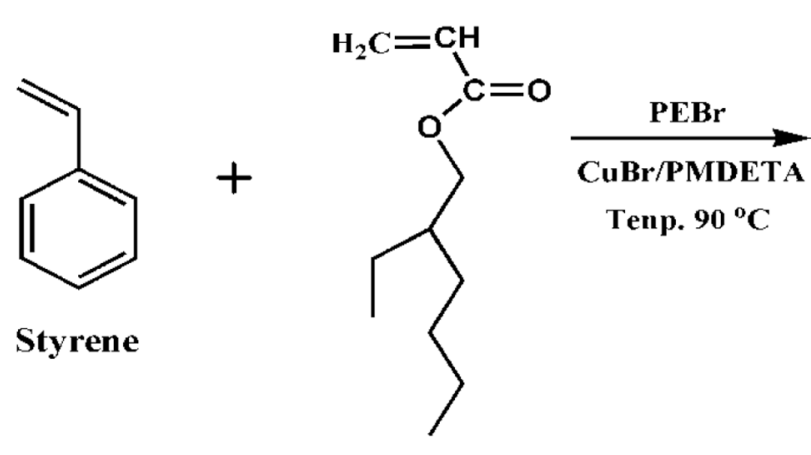

2-ethylhexyl acrylate (EHA)

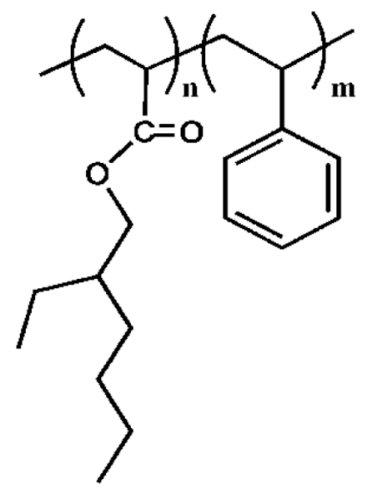

Poly(styrene-co-EHA)

Scheme 1 | Copolymerization of styrene and EHA via atom transfer radical polymerization (ATRP). 
macromolecular chain having EHA active radical as the terminal unit and EHA and $\mathrm{k}_{21}$ is the rate constant of the reaction between EHA active radical and styrene monomer (cross propagation). For determining the $r_{1}$ and $r_{2}$, copolymerization of styrene and EHA was carried out at different feed ratio of styrene (1) and EHA

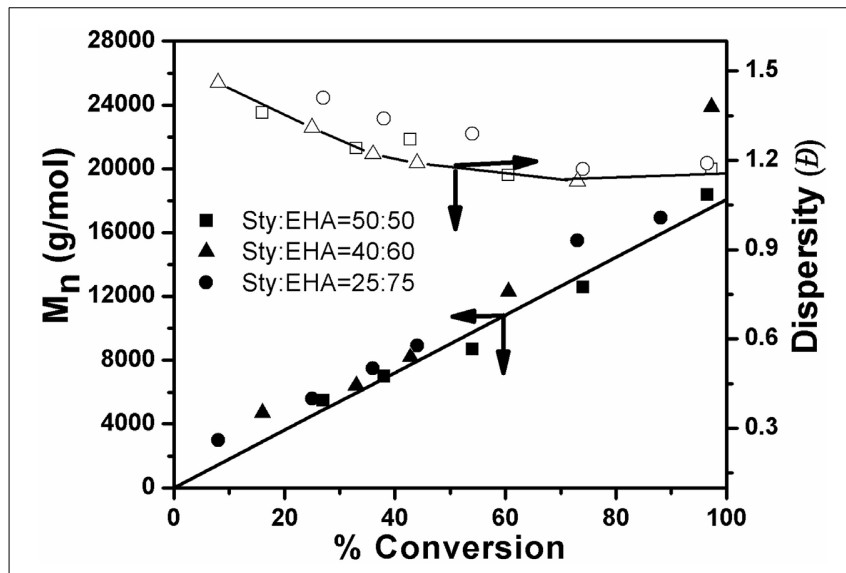

FIGURE 2 | Plot of $\boldsymbol{M}_{\mathbf{n}}$ and $\boldsymbol{\boldsymbol { \theta }}$ vs. conversion (\%) for ATRcP of Styrene and EHA in bulk. [PEBr]: [M] $]_{\circ}:[\mathrm{CuBr}]:[\mathrm{PMDETA}]=1: 100: 1: 1$, at $90^{\circ} \mathrm{C}$.

Table 1 | Copolymerization of styrene and EHA in bulk at $90^{\circ} \mathrm{C}$.

\begin{tabular}{lccccc}
\hline SI. No. & $\begin{array}{c}\text { Feed } \\
\text { composition (\%) } \\
\text { styrene: EHA }\end{array}$ & $\begin{array}{c}\text { Copolymer } \\
\text { composition } \neq \\
\text { (\%) styrene: EHA }\end{array}$ & $\begin{array}{c}\text { Conversion } \\
(\%)\end{array}$ & $\begin{array}{c}\boldsymbol{M}_{\boldsymbol{n}, \mathrm{GPC}} \\
(\mathbf{g} / \mathbf{m o l})\end{array}$ & $\boldsymbol{\theta}$ \\
\hline 1 & $25: 75$ & $27: 73$ & 98.1 & 16,900 & 1.27 \\
2 & $40: 60$ & $44: 56$ & 88.0 & 24,000 & 1.15 \\
3 & $50: 50$ & $56.6: 43.4$ & 97.8 & 18,500 & 1.17 \\
\hline
\end{tabular}

$[\mathrm{PEBr}]:[\mathrm{M}]_{0}:[\mathrm{CUBr}]:[\mathrm{PMDETA}]=1: 100: 1: 1$. Reaction time $=2 \mathrm{~h} 20 \mathrm{~min}$.

* Compositions were calculated by ${ }^{1} \mathrm{H}$ NMR spectroscopy.
(2). In this case copolymerization was carried out at low conversion $(\sim 10 \%)$ and its molar composition was determined by ${ }^{1} \mathrm{H}$ NMR spectroscopy. Composition of the low conversion copolymer was used for the determination of monomer reactivity ratios. In this case FR, IFR, and KT methods were used to determine the reactivity ratio of the monomers.

In the FR method the following equation was used

$$
\mathrm{M}-\frac{\mathrm{M}}{\mathrm{P}}=-\mathrm{r}_{2}+\mathrm{r}_{1} \frac{\mathrm{M}^{2}}{\mathrm{P}}
$$

where, $\mathrm{M}=$ molar feed ratio $\left(\mathrm{M}_{1} / \mathrm{M}_{2}\right)$ and $\mathrm{P}=$ copolymer composition $\left(\mathrm{m}_{1} / \mathrm{m}_{2}\right)$

$$
\text { or, } \mathrm{G}=-\mathrm{r}_{2}+\mathrm{r}_{1} \mathrm{H}
$$

where, $\mathrm{G}=\mathrm{M}-\mathrm{M} / \mathrm{P}$ and $\mathrm{H}=\mathrm{M}^{2} / \mathrm{P}$

The plot of $\mathrm{G}$ vs. $\mathrm{H}$ gives the straight line (Figure 4). From this the slope and intercept were calculated to be $\mathrm{r}_{1}=1.24$ and $\mathrm{r}_{2}=0.71$ respectively.

In the IFR method the equation used is

$$
\frac{\mathrm{G}}{\mathrm{H}}=-\mathrm{r}_{2} \frac{1}{\mathrm{H}}+\mathrm{r}_{1}
$$

So, from the plot of $\mathrm{G} / \mathrm{H}$ and $1 / \mathrm{H}$ (Figure 5 ) the reactivity ratios, $r_{1}$ and $r_{2}$ were calculated as 1.34 and 0.76 from the intercept and the slope respectively.

In KT method the reactivity ratio was determined by using the equation

$$
\eta=\left(r_{1}+\frac{r_{2}}{\propto}\right) \xi-\frac{r_{2}}{\propto}
$$

where, $\eta=\mathrm{G} /(\propto+\mathrm{H})$ and $\xi=\mathrm{H} /(\propto+\mathrm{H})$ and $\propto=\left(\mathrm{H}_{\min }\right.$. $\left.\mathrm{H}_{\max }\right)^{1 / 2}, \mathrm{H}_{\min }=0.253$ and $\mathrm{H}_{\max }=0.775$. $\mathrm{H}_{\min }$ and $\mathrm{H}_{\max }$ values are taken from Table 2 .
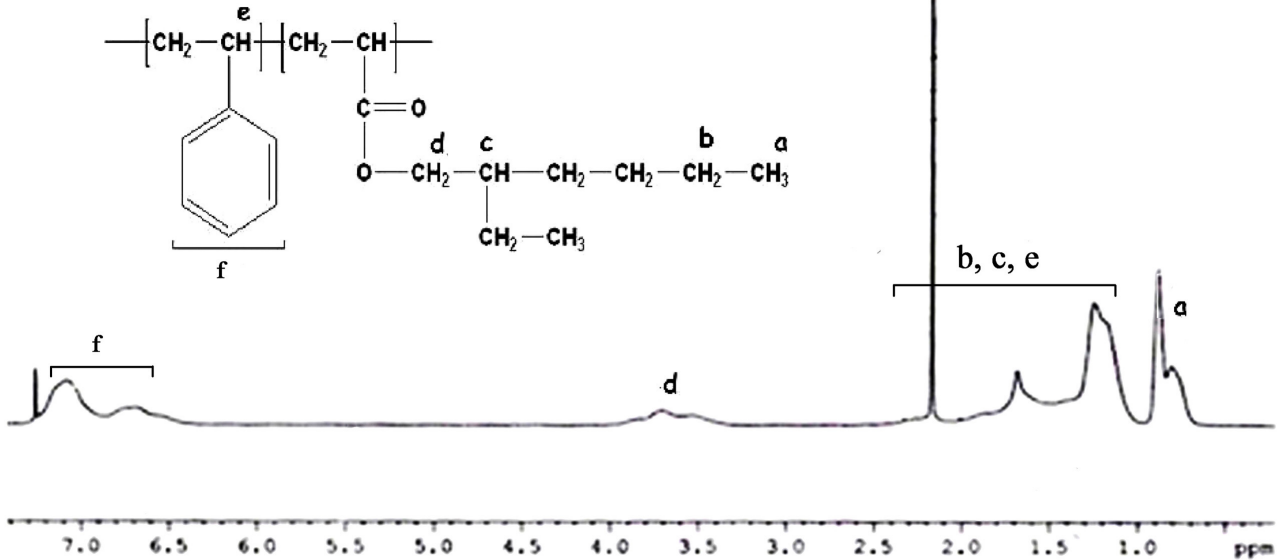

FIGURE 3 | ${ }^{1} \mathrm{H}$ NMR spectrum of poly(styrene-co-EHA) with feed molar composition 50:50. 
In the plot of $\eta$ vs. $\xi$, (Figure 6) the slope gives the value of $\left(r_{1}+r_{2} / \propto\right)$ and intercept provides $r_{2} / \propto$. From these two values $r_{1}$ and $r_{2}$ were calculated as $r_{1}=1.30$ and $r_{2}=0.73$ respectively. All the parameters used for the three methods are given in Table 2 .

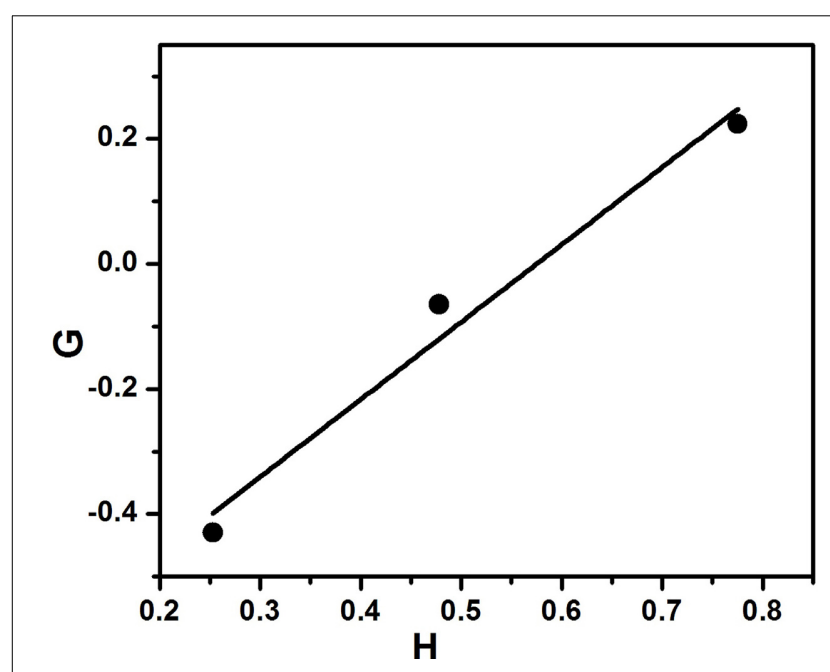

FIGURE 4 | Finemann-Ross plot for copolymerization of styrene with EHA.

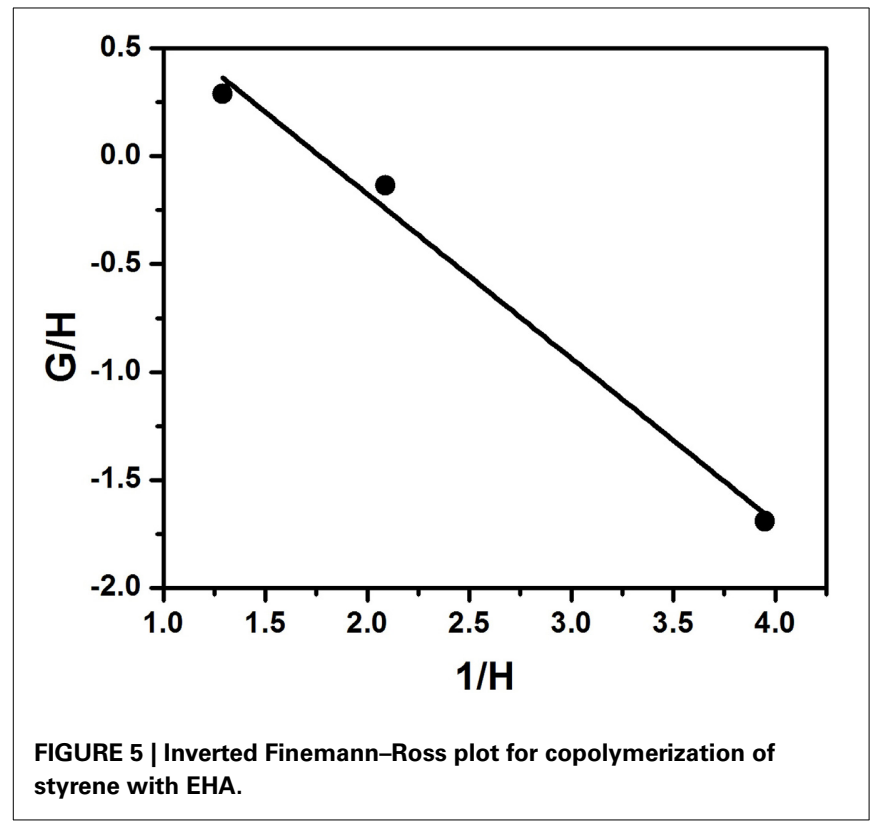

The reactivity ratios, $\mathrm{r}_{1}$ and $\mathrm{r}_{2}$ calculated by the different methods are tabulated in Table 3. They are quite comparable. The values; $r_{1}>1, r_{2}<1$ and $r_{2}<r_{1}$ indicate that the styrene has much influence on the copolymer formation during the reaction (Jianying et al., 2006). Srivastava et al. (Srivastava and Rai, 1995) reported the copolymerization of styrene and EHA initiated by azobisisobutyronitrile (AIBN) in bulk in the presence of anhydrous $\mathrm{ZnCl}_{2}$. They reported the reactivity ratios for styrene and EHA as 0.10 and 0.175 respectively. Moreover, Kavousian et al. reported the copolymerization of styrene and EHA via conventional radical polymerization (Kavousian et al., 2004). They reported the reactivity ratio of styrene and EHA as 0.926 and 0.238 respectively. There is a difference in the polymerization mechanism of ATRP and non-ATRP processes. In ATRP, atom transfer from an organic halide to a transition metal complex occurs to generate the active radical species, which are

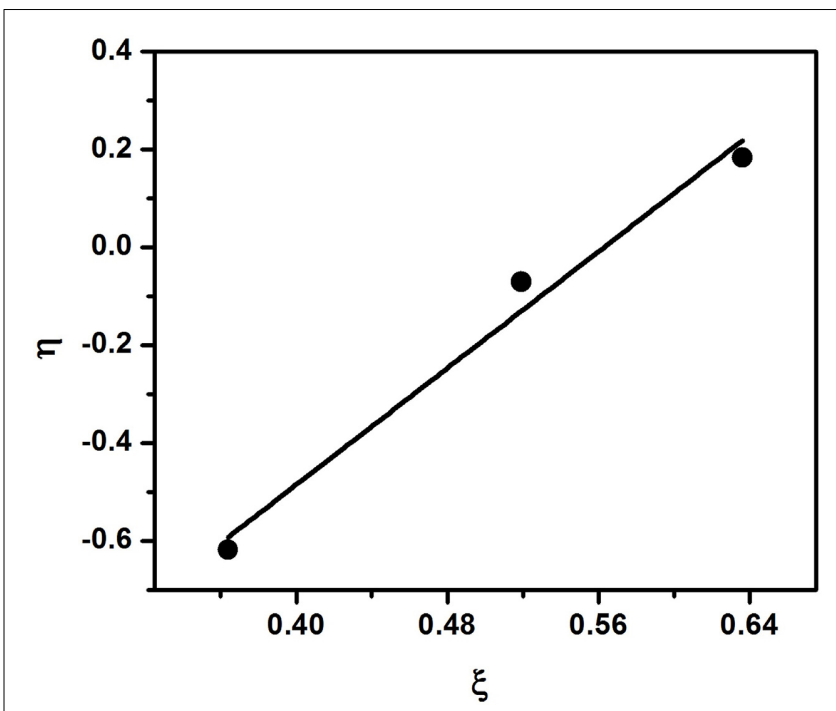

FIGURE 6 | Kelen-Tudos plot for copolymerization of styrene with EHA.

Table 3 | Reactivity ratio of styrene $\left(r_{1}\right)$ and EHA $\left(r_{2}\right)$ determined by three different models.

\begin{tabular}{lccc}
\hline Methods used & $\mathbf{r}_{\mathbf{1}}$ (styrene) & $\mathbf{r}_{\mathbf{2}}$ (EHA) & $\mathbf{r}_{\mathbf{1}} \cdot \mathbf{r}_{\mathbf{2}}$ \\
\hline FR & 1.24 & 0.71 & 0.88 \\
IFR & 1.34 & 0.76 & 1.01 \\
KT & 1.30 & 0.73 & 0.91
\end{tabular}

Table 2 | Finemann-Ross, Inverted Finemann-Ross and Kelen-Tudos parameter for the copolymer of styrene and EHA in bulk* .

\begin{tabular}{|c|c|c|c|c|c|c|c|c|c|c|c|}
\hline Monomer feed ratio styrene: EHA & $M=M_{1} / M_{2}$ & ${ }^{\#} P=m_{1} / m_{2}$ & $M / P$ & P-1 & $\boldsymbol{G}$ & $\boldsymbol{H}$ & $G / H$ & $1 / H$ & $\propto+\mathbf{H}$ & $\eta$ & $\xi$ \\
\hline $40: 60$ & 0.66 & 0.91 & 0.725 & -0.09 & -0.065 & 0.478 & -0.135 & 2.09 & 0.920 & -0.070 & 0.519 \\
\hline
\end{tabular}

${ }^{*}[\mathrm{PEBr}]:[\mathrm{M}]_{0}:[\mathrm{CUBr}]:[\mathrm{PMDETA}]=1: 100: 1: 1$, at $90^{\circ} \mathrm{C}$ (where, $\left.\propto=0.442\right)$.

\#Copolymer composition at 10\% conversion. 
Table 4 | The monomer composition and sequence length ratio.

\begin{tabular}{lccccc}
\hline Copolymer feed ratio styrene: EHA & $\mathbf{M}_{\mathbf{1}} / \mathbf{M}_{\mathbf{2}}$ & $\mathbf{M}_{\mathbf{2}} / \mathbf{M}_{\mathbf{1}}$ & $\mathbf{I}_{\mathbf{1}}$ & $\mathbf{I}_{\mathbf{2}}$ & $\mathbf{I}_{\mathbf{1}}: \mathbf{I}_{\mathbf{2}}$ \\
\hline $25 / 75$ & 0.33 & 3.00 & 1.42 & 3.19 & $4: 9$ \\
$40 / 60$ & 0.66 & 1.50 & 1.85 & 2.09 & $4: 5$ \\
$50 / 50$ & 1.00 & 1.00 & 2.29 & 1.73 & $4: 3$
\end{tabular}

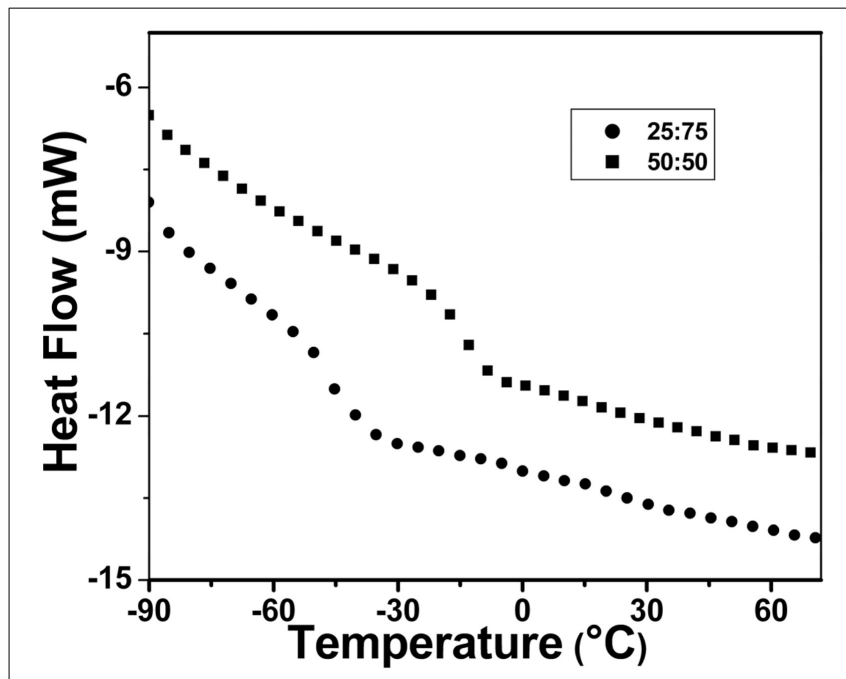

FIGURE 7 | DSC thermogram of poly(styrene-co-EHA).

Table 5 | Thermal properties of copolymers of styrene and EHA.

\begin{tabular}{llccccc}
\hline $\begin{array}{l}\text { SI. Feed } \\
\text { no. } \begin{array}{l}\text { composition } \\
\text { styrene: EHA }\end{array}\end{array}$ & $\begin{array}{c}\text { Copolymer } \\
\text { composition } \\
\text { styrene: EHA }\end{array}$ & $\begin{array}{c}\boldsymbol{T}_{\mathbf{g}} \\
\left({ }^{\circ} \mathbf{C}\right)\end{array}$ & $\begin{array}{c}{ }^{*} \boldsymbol{T}_{\mathbf{g}, \mathrm{F}-\mathrm{F}} \\
\left({ }^{\circ} \mathbf{C}\right)\end{array}$ & $\begin{array}{c}{ }^{*} \boldsymbol{T}_{\text {onset }} \\
\left({ }^{\circ} \mathbf{C}\right)\end{array}$ & $\begin{array}{c}\boldsymbol{T}_{\text {max }} \\
\left({ }^{\circ} \mathbf{C}\right)\end{array}$ \\
\hline 1 & $25: 75$ & $27: 73$ & -47 & -36 & 381 & 409 \\
2 & $40: 60$ & $44: 56$ & -27 & -18 & 389 & 414 \\
3 & $50: 50$ & $56.6: 43.4$ & -14 & -5 & 385 & 415 \\
4 & Polystyrene-b-PEHA & $85: 15$ & +123 and -65 & - & - & - \\
\hline
\end{tabular}

${ }^{*} T_{g, F-F}$ was calculated by using Flory-Fox equation.

\# Temperature at $10 \%$ weight loss was taken as $T_{\text {onset }}$.

$T_{\text {max }}$ represents the maximum degradation temperature at which the polymer back-bone starts degrading. It was determined from the DTG thermogram.

then quickly "deactivated" by back transfer of the atom from the transition metal to the radical species (Matyjaszewski, 2002; Braunecker and Matyjaszewski, 2007). So, there is difference in reactivity ratio values in comparison to FRP. Barim et al. studied the FRP and ATRP of phenoxycarbonylmethyl methacrylate (PCMMA) and styrene at $110^{\circ} \mathrm{C}$. They reported the reactivity ratios of PCMMA and styrene prepared via ATRP were 0.33 and 0.96 respectively and the same prepared via FRP were 0.47 and 1.16 respectively (Barim et al., 2007). The reactivity ratio varies with the polymerization temperature (Chambard et al., 1999; McManus et al., 2002). We did the polymerization reaction via ATRP in bulk at $90^{\circ} \mathrm{C}$. However, the reactivity ratios calculated in this work follow the same trend $\left(\mathrm{r}_{\mathrm{EHA}}<\mathrm{r}_{\text {Styrene }}\right)$ as reported by the other authors. In addition, in ATRcP technique the product of

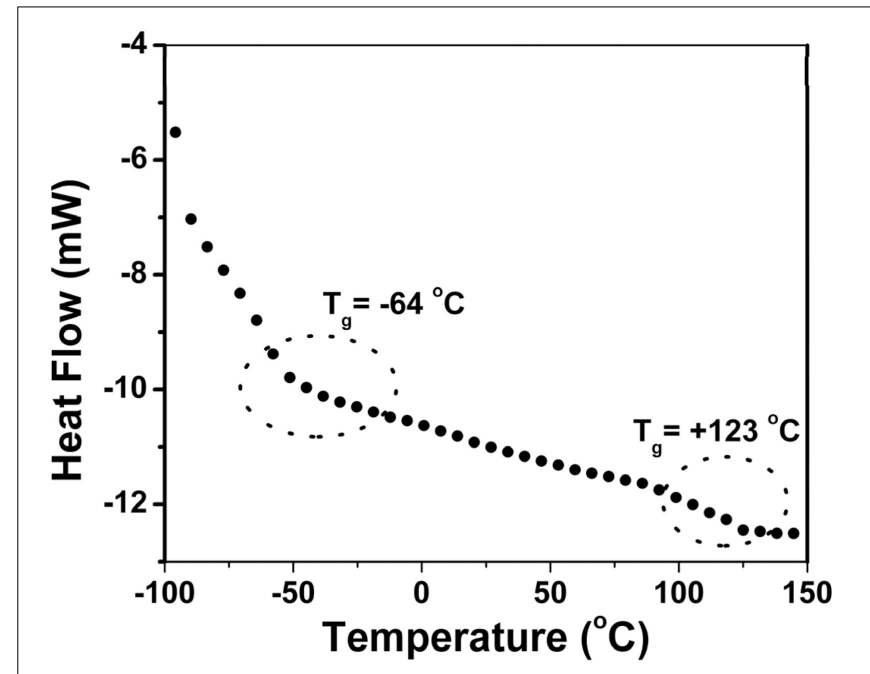

FIGURE 8 | DSC thermogram of the polystyrene- $b$-PEHA.

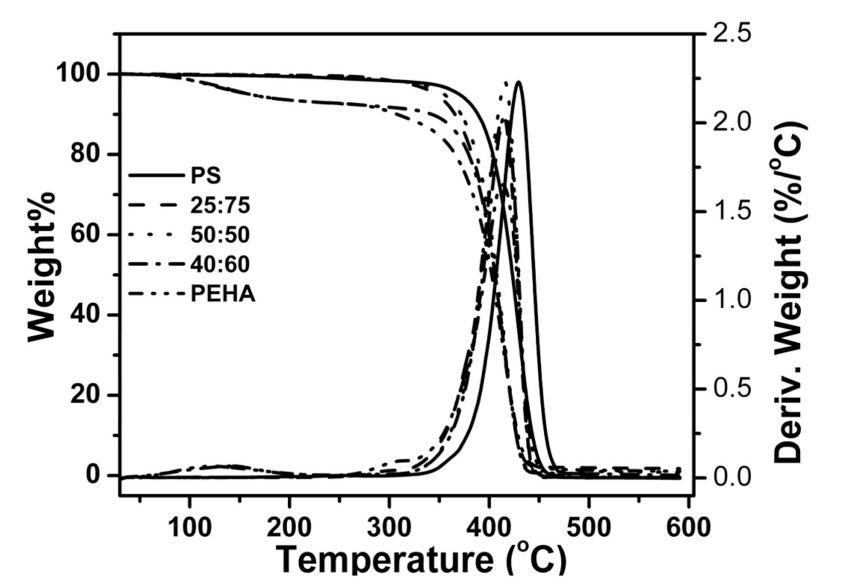

FIGURE 9 | TGA thermogram of homopolymer and copolymers of styrene and EHA.

the reactivity ratios is less than one. It shows the tendency of random copolymer formation, where the chances of incorporation of styrene is more in comparison to EHA.

The mean sequence length (1) of the copolymers were determined by using the equations (Pazhanisamy et al., 1997)

$$
l_{1}=\mathrm{r}_{1} \frac{\mathrm{M}_{1}}{\mathrm{M}_{2}}+1
$$

and

$$
l_{2}=\mathrm{r}_{2} \frac{\mathrm{M}_{2}}{\mathrm{M}_{1}}+1
$$

where, $\mathrm{r}_{1}$ (styrene) $=1.29$ and $\mathrm{r}_{2}(\mathrm{EHA})=0.73$

The results of the mean sequence length in the copolymer are shown in Table 4. It indicates that the length of EHA increases as its content in the monomer feed increases. 


\section{THERMAL PROPERTIES}

The glass transition temperature $\left(T_{\mathrm{g}}\right)$ of the copolymer was determined by DSC analysis (shown in Figure 7). All the copolymers showed a single $T_{\mathrm{g}}$ and they are shown in Table 5. It indicates that as the $\mathrm{EHA}\left(T_{\mathrm{g}}=-60^{\circ} \mathrm{C}\right)$ content increases the $T_{\mathrm{g}}$ decreases. The $T_{\mathrm{g}}$ for the copolymers determined by DSC analysis was compared with the same $\left(T_{\mathrm{g}, \mathrm{F}-\mathrm{F}}\right)$ determined by Flory-Fox equation (Lijia et al., 1997). There is consistent difference between the $T_{\mathrm{g}}$ values at different content of two comonomers (Table 5). Table 5 shows that there is some discrepancy between the experimental $T_{\mathrm{g}}$ and $T_{\mathrm{g}}$ calculated by Flory-Fox equation. The FloryFox model is based on the free volume theory. The discrepancy in the $T_{\mathrm{g}}$ values is due to the fact that the effect of the chemical nature and organization of the monomers on the mobility of a polymer chain was not considered (Fernandez-Garcia et al., 1999).

The block copolymer of styrene and EHA (PS- $b$-PEHA) was prepared by using polystyrene-Br as macroinitiator. The shift of GPC traces of the diblock copolymer toward lower elution volume indicated the successful preparation of block copolymer. (The GPC traces are shown in Figure S2). This block copolymer showed two $T_{\mathrm{g}} \mathrm{s}$, PEHA block at $-64^{\circ} \mathrm{C}$ and polystyrene at $+123^{\circ} \mathrm{C}$ (Figure 8). However, the copolymers, poly(styrene-coEHA) showed only one $T_{\mathrm{g}}$ indicating the copolymers were not blocky in nature. Thermal stability of the copolymer was studied by TGA (Figure 9). It is clear that as the styrene content increases, there is a slight increase in $T_{\text {onset }}$. However, there was no significant change in $T_{\max }$ as shown in Table 5.

\section{CONCLUSIONS}

Copolymers of styrene and 2-ethylhexyl acrylate were synthesized successfully in bulk by using atom transfer radical copolymerization (ATRcP). The chemical composition was studied by ${ }^{1} \mathrm{H}$ NMR spectroscopy and the reactivity ratios of the two monomers were calculated by using FR, IFR, and KT methods. The reactivity ratios of styrene and EHA were somewhat different from the polymerization reaction of styrene and EHA using the FRP system. DSC analysis showed that the $T_{\mathrm{g}}$ of the copolymer increases on increasing styrene content.

\section{ACKNOWLEDGMENT}

Bishnu P. Koiry gratefully acknowledges the fellowship from IIT, Kharagpur, India.

\section{SUPPLEMENTARY MATERIAL}

The Supplementary Material for this article can be found online at: http://www.frontiersin.org/journal/10.3389/fchem. 2014.00091/abstract

\section{Figure S1 | GPC traces of poly(styrene-co-EHA), sample 3 of Table 1.}

Figure S2 | GPC traces of polystyrene macroinitiator and polystyrene-b-PEHA block copolymer.

\section{REFERENCES}

Arehart, S. V., and Matyjaszewski, K. (1999). Atom transfer radical copolymerization of styrene and n-butyl acrylate. Macromolecules 32, 2221-2231. doi: $10.1021 / \mathrm{ma981693v}$

Barim, G., Demirelli, K., and Coskun, M. (2007). Conventional and atom transfer radical copolymerization of phenoxycarbonylmethyl methacrylate-styrene and thermal behavior of their copolymers. Express Polym. Lett. 1, 535-544. doi: 10.3144/expresspolymlett.2007.76

Barner-Kowollik, C. (2008). Handbook of RAFT Polymerization. Weinheim: WileyVCH Verlag GmbH and Co. KGaA. doi: 10.1002/9783527622757

Braunecker, W. A., and Matyjaszewski, K. (2007). Controlled/living radical polymerization: features, developments, and perspectives. Prog. Polym. Sci. 32, 93-146. doi: 10.1016/j.progpolymsci.2006.11.002

Chambard, G., Klumperman, B., and German, A. L. (1999). Dependence of chemical composition of styrene/butyl acrylate copolymers on temperature and molecular weight. Polymer 40, 4459-4463. doi: 10.1016/S0032-3861(98) 00690-9

Chiefari, J., Chong, Y. K., Ercole, F., Krstina, J., Jeffery, J., Le, T. P. T., et al. (1998). Living free-radical polymerization by reversible additionfragmentation chain transfer: the RAFT process. Macromolecules 31, 5559-5562. doi: $10.1021 / \mathrm{ma} 9804951$

Fernandez-Garcia, M., Cuervo-Rodriguez, R., and Madruga, E. L. (1999). Glass transition temperatures of butyl acrylate-methyl methacrylate copolymers. J. Polym. Sci. B Polym. Phys. 37, 2512-2520. doi: 10.1021/ma001182k

Fineman, M., and Ross, S. D. (1950). Liner method for determining monomer reactivity ratios in copolymerization. J. Polym. Sci. 5, 259-262. doi: 10.1002/pol.1950.120050210

Haldankar, G. S. (2001). Compatibilizer for Polymer Blends. Frankfort, IL: The Sherwin-Williams Co. US Patent 6,541,571.

Haloi, D. J., Roy, S., and Singha, N. K. (2009). Copper catalyzed atom transfer radical copolymerization of glycidyl methacrylate and 2-ethylhexyl acrylate. J. Polym. Sci. A Polym. Chem. 47, 6526-6533. doi: 10.1002/pola.23695

Harth, E., Horn, B. V., and Hawker, C. J. (2001). Acceleration in nitroxide mediated 'living' free radical polymerizations. Chem. Commun. 9, 823-824. doi: 10.1039/b102145c

Hawker, C. J., Bosman, A. W., and Harth, E. (2001). New polymer synthesis by nitroxide mediated living radical polymerization. Chem. Rev. 101, 3661-3688. doi: 10.1021/cr990119u

Jianying, H., Jiayan, C., Jiaming, Z., Yihong, C., Lizong, D., and Yousi, Z. (2006). Some monomer reactivity ratios of styrene and (meth)acrylates in the presence of TEMPO. J. Appl. Polym. Sci. 100, 3531-3535. doi: 10.1002/app.22512

Kamigaito, M., Ando, T., and Sawamoto, M. (2001). Metal-catalyzed living radical polymerization. Chem. Rev. 101, 3689-3745. doi: 10.1021/cr99 01182

Kavitha, A., and Singha, N. K. (2007). Atom-transfer radical copolymerization of furfuryl methacrylate (FMA) and methyl methacrylate (MMA): a thermally-amendable copolymer. Macromol. Chem. Phys. 208, 2569-2577. doi: 10.1002/macp.200700239

Kavitha, A., and Singha, N. K. (2008). High temperature resistant tailormade poly(meth)acrylates bearing adamantyl group via atom transfer radical polymerization. J. Polym. Sci. A Polym. Chem. 46, 7101-7113. doi: 10.1002/pola.23015

Kavousian, A., Ziaee, F., Nekoomanesh, H., Leamen, M. J., and Penlidis, A. (2004). Determination of monomer reactivity ratios in styrene/2-ethylhexylacrylate copolymer. J. Appl. Polym. Sci. 92, 3368-3370. doi: 10.1002/app. 20338

Kelen, T., Tudos, F., and Turcsanyi, B. (1980). Confidence intervals for copolymerization reactivity ratios determined by the Kelen-Tudos method. Polym. Bull. 2, 71-76. doi: 10.1007/BF00275556

Lessard, B., Graffe, A., and Maric, M. (2007). Styrene/t-Butyl acrylate random copolymers synthesized by nitroxide-mediated polymerization: effect of free nitroxide on kinetics and copolymer composition. Macromolecules 40, 9284-9292. doi: 10.1021/ma071689w

Lijia, A. N., Dayong, H. E., Jlaokai, J., Zhigang, W., Donghong, Y. U., Jiang, B., et al. (1997). Effects of molecular weight and interaction parameter on the glass transition temperature of polystyrene mixture and its blends with polystyrene/poly(2,6-dimethyl-p-phenylene oxide). Eur. Polym. J. 33, 1523-1528. doi: 10.1016/S0014-3057(97)00089-X

Makrikosta, G., Georgas, D., Siakali-Kioulafa, E., and Pitsikalis, M. (2005). Statistical copolymers of styrene and 2-vinylpyridine with trimethylsilyl methacrylate and trimethylsilyloxyethyl methacrylate. Eur. Polym. J. 41, 47-54. doi: 10.1016/j.eurpolymj.2004.08.001

Matyjaszewski, K. (2000). "Controlled/Living radical polymerisation: progress in ATRP, NMP and RAFT," in ACS Symposium Series (New Orleans, LA). doi: 10.1021/bk-2000-0768 
Matyjaszewski, K. (2002). Factors affecting rates of comonomer consumption in copolymerization processes with intermittent activation. Macromolecules 35, 6773-6781. doi: 10.1021/ma0208180

Matyjaszewski, K., and Jia, J. (2001). Atom transfer radical polymerization. Chem. Rev. 101, 2921-2990. doi: 10.1021/cr940534g

McManus, N. T., Penlidis, A., and Dube, M. A. (2002). Copolymerization of alpha-methyl styrene with butyl acrylate in bulk. Polymer 43, 1607-1614. doi: 10.1016/S0032-3861(01)00738-8

Mignard, E., Leblanc, T., Bertin, D., Guerret, O., and Reed, W. F. (2004). Online monitoring of controlled radical polymerization: nitroxide-mediated gradient copolymerization. Macromolecules 37, 966-975. doi: 10.1021/ ma035589b

Moad, G. (2006). The emergence of RAFT polymerization. Aust. J. Chem. 59, 661-662. doi: 10.1071/CH06376

Moad, G., Chiefari, J., Chong, Y. K., Krstina, J., Mayadunne, R. T. A., Postma, A., et al. (2000). Living free radical polymerization with reversible additionfragmentation chain transfer (the life of RAFT). Polym. Int. 49, 993-1001. doi: 10.1002/1097-0126(200009)49:9<993::AID-PI506>3.0.CO;2-6

Odian, G. (2004). Principles of Polymerization. New Jersey, NJ: Wiley-Interscience publication. doi: 10.1002/047147875X

Pazhanisamy, P., Ariff, M., and Anwaruddin, Q. (1997). Copolymers of $\alpha$ methylstyrene with $N$-cyclohexylacrylamide: synthesis, monomer reactivity ratios, and mean sequence length. J. Macromol. Sci. A Pure Appl. Chem. A34, 1045-1054. doi: 10.1080/10601329708015009

Plessis, C., Arzamendi, G., Alberdi, J. M., Agnely, M., Leiza, J. R., and Asua, J. M. (2001). Intramolecular chain transfer to polymer in the emulsion polymerization of 2-ethylhexyl acrylate. Macromolecules 34, 6138-6143. doi: $10.1021 / \mathrm{ma0018190}$

Skeist, I. (1977). Handbook of Adhesives. New York, NY: Chapman \& Hall.
Solomon, D. H., and Moad, G. (1995). The Chemistry of Free Radical Polymerization. Oxford: Elsevier Science Ltd.

Srivastava, N., and Rai, J. S. P. (1995). Kinetics, mechanism, and rheological properties of the copolymers of 2-ethylhexylacrylate and styrene. J. Macromol. Sci. A Pure Appl. Chem. A32, 2049-2062. doi: 10.1080/10601329508011044

Webster, D. C., and Crain, A. L. (2002). Synthesis of latexes containing diesters of 3-butene-1,2-diol. Prog. Org. Coat. 45, 43-48. doi: 10.1016/S0300-9440(02) 00099-1

Ziegler, M. J., and Matyjaszewski, K., (2001). Atom transfer radical copolymerization of methyl, methacrylate and n-butyl acrylate. Macromolecules 34, 415-424. doi: $10.1021 / \mathrm{ma} 001182 \mathrm{k}$

Conflict of Interest Statement: The authors declare that the research was conducted in the absence of any commercial or financial relationships that could be construed as a potential conflict of interest.

Received: 16 June 2014; accepted: 25 September 2014; published online: 17 October 2014.

Citation: Koiry BP and Singha NK (2014) Copper mediated controlled radical copolymerization of styrene and 2-ethylhexyl acrylate and determination of their reactivity ratios. Front. Chem. 2:91. doi: 10.3389/fchem.2014.00091

This article was submitted to Polymer Chemistry, a section of the journal Frontiers in Chemistry.

Copyright (c) 2014 Koiry and Singha. This is an open-access article distributed under the terms of the Creative Commons Attribution License (CC BY). The use, distribution or reproduction in other forums is permitted, provided the original author(s) or licensor are credited and that the original publication in this journal is cited, in accordance with accepted academic practice. No use, distribution or reproduction is permitted which does not comply with these terms. 